\title{
Perancangan Sistem E-Voting Pemilihan Ketua Bem Fakultas Teknik Universitas Sulawesi Barat
}

\author{
Risdayanti*1, Heliawati Hamrul ${ }^{2}$, Dian Megah Sari ${ }^{3}$ \\ 1,2,3 Program Studi Teknik Informatika Universitas Sulawesi Barat \\ e-mail: ${ }^{* 1}$ risdayantijafar6@gmail.com, ${ }^{2}$ heliawatihamrul@ unsulbar.ac.id, \\ 3dianmegahsari@unsulbar.ac.id
}

\begin{abstract}
Abstrak
Sistem pemilihan ketua organisasi di lingkungan Fakultas Teknik Unsulbar masih dilakukan secara konvensional Kegiatan voting yang dilakukan secara konvensional memiliki kekurangan seperti proses yang lambat karena banyak persiapan yang harus dikerjakan sedangkan pengerjaannya masih dilakukan secara manual, besarnya anggaran yang dibutuhkan untuk membiayai seluruh keperluan untuk melaksanakan voting, kurang akuratnya proses perhitungan suara dan pemilih dituntut untuk hadir secara langsung untuk memberikan hak suaranya Berbagai masalah dalam proses pemungutan suara dapat diatasi dengan menerapkan Teknologi Informasi dan Komunikasi (TIK), yaitu E-voting (electronic voting). E-voting dianggap lebih mudah dan lebih efisien dikarenakan semua prosesnya sudah dilakukan oleh computer[2]. E-voting juga mempermudah dalam proses penghitungan suara, karena dilakukan secara online maka suara hasil pemilihan yang masuk bisa langsung diketahui tanpa harus menghitung kertas suara seperti proses pemilihan secara manual Dalam proses pembuatan dan perancangan Sistem e-voting pemilihan ketua BEM pada Fakultas teknik UNSULBAR berbasis web dibangun dengan menggunakan metode pengembangan sistem waterfall, bahasa pemrograman PHP dan menggunakan database MySql. Sistem ini dapat membantu panitia KPUM dapat melakukan proses pemilihan ketua BEM dengan mudah dan cepat mampu mengurangi permasalahan pada sistem pemilihan konvensional.
\end{abstract}

Kata Kunci - E-Voting, BEM, PHP, RSA,Mysql

\begin{abstract}
The system for selecting the head of the organization within the Faculty of Engineering, Unsulbar is still done conventionally. Voting activities carried out conventionally have drawbacks such as a slow process because there is a lot of preparation that must be done while the process is still done manually, the amount of budget needed to finance all the needs to carry out voting, less accurate vote counting process and voters are required to attend in person to cast their votes Various problems in the voting process can be overcome by applying Information and Communication Technology (ICT) [2], namely E-voting (electronic voting). E-voting is considered easier and more efficient because all the processes have been carried out by computers. E-voting also simplifies the vote counting process, because it is done online, the incoming election results can be directly identified without having to count ballots such as the manual selection process. The web was built using the waterfall system development method, the PHP programming language and using the MySql database. This system is expected so that the KPUM committee can carry out the process of selecting the chairman of the BEM easily and quickly to reduce problems in the conventional election system.
\end{abstract}

Keywords - E-Voting, BEM, PHP, RSA,Mysql 


\section{PENDAHULUAN}

Teknologi pada saat ini berkembang dengan begitu pesatnya. Berbagai informasi dan pengelolaan manajemen instansi saat ini sangat mendukung untuk bisa dikembangkan menjadi sistem yang mengandalkan kemajuan teknologi[2]. Pada lembaga pendidikan tidak akan lepas dari kegiatan pengolahan data, baik secara manual maupun dengan terkomputerisasi. Pengolahan data merupakan suatu hal rutinitas lembaga pendidikan, khususnya pada Universitas Sulawesi Barat. Sehingga perlu dibudayakan sistem informasi dengan baik untuk pengelolaan pemilihan suara.

Voting merupakan sebuah metode yang digunakan untuk pengambilan keputusan. Kegiatan voting dilakukan untuk menghimpun aspirasi dengan tujuan menentukan jalan keluar yang dianggap paling baik dalam menyelesaikan permasalahan[2]. Kegiatan voting yang secara luas dikenal oleh masyarakat adalah pemilu atau pilkada yang diselenggarakan oleh KPU, namun kegiatan voting sering pula dilakukan dalam skala yang lebih kecil contohnya pemilihan ketua organisasi di lingkungan Fakultas Teknik Unsulbar. Pemilihan ketua organisasi di lingkungan Fakultas Teknik Unsulbar dilaksanakan setelah berakhir periode masa jabatan atau lebih kurang 1 tahun. Ketua organisasi dipilih oleh mahasiswa pada saat berlangsungnya kongres besar mahasiswa atau musyawarah anggota. Pemilihan ketua organisasi di lingkungan Fakultas Teknik Unsulbar masih dilakukan secara konvensional. Kegiatan voting yang dilakukan secara konvensional memiliki kekurangan seperti proses yang lambat karena banyak persiapan yang harus dikerjakan sedangkan pengerjaannya masih dilakukan secara manual, besarnya anggaran yang dibutuhkan untuk membiayai seluruh keperluan untuk melaksanakan voting, kurang akuratnya proses perhitungan suara dan pemilih dituntut untuk hadir secara langsung untuk memberikan hak suaranya.

Pemungutan suara E-voting merupakan pemungutan suara yang proses pelaksanaannya mulai dari pendaftaran pemilih, pelaksanaan pemilihan, perhitungan suara dan pengiriman hasil suara dilaksanakan secara elektronik (digital) [8]. Berbagai masalah dalam proses pemungutan suara dapat diatasi dengan menerapkan Teknologi Informasi dan Komunikasi (TIK), yaitu electronic voting. E-voting dianggap lebih mudah dan lebih efisien dikarenakan semua prosesnya sudah dilakukan oleh komputer[6]. E-voting juga mempermudah dalam proses penghitungan suara, karena dilakukan secara online maka suara hasil pemilihan yang masuk bisa langsung diketahui tanpa harus menghitung kertas suara seperti proses pemilihan secara manual.

\section{METODE}

Metode pengembangan sistem yang digunakan pada penelitian ini yaitu waterfall atau yang sering disebut metode air terjun dimana proses pengembangan perangkat lunak berurutan, melewati fase-fase perencanaan, pemodelan, implementasi (konstruksi), dan pengujian(Turisto, 1942)[4]. Adapun model waterfall sebagai berikut. Berikut uraian dari tahapan penelitian pada gambar 1.

1. Analisis kebutuhan sistem

Langkah ini merupakan analisa terhadap kebutuhan sistem. Pada tahap ini pengembang harus mengetahui seluruh informasi mengenai kebutuhan software seperti kegunaan software yang diinginkan oleh pengguna dan batasan software. Pengumpulan data dalam tahap ini bisa melakukan sebuah penelitian, wawancara atau studi literatur. Adapun hasil wawancara yang didapatkan berupa uraian sistem yang telah berjalan pada pemilihan ketua bem pada saat ini yang masih konvensional. 
2. Desain

Desain dilakukan sebelum proses coding dimulai. Ini bertujuan untuk memberikan gambaran lengkap tentang apa yang harus dikerjakan dan bagaimana tampilan dari sebuah sistem yang diinginkan.Sehingga membantu menspesifikan kebutuhan hardware dan sistem, juga mendefinisikan arsitektur sistem yang akan dibuat secara keseluruhan. Dalam penelitian ini desain sistem berfokus pada sistem pemilihan yang digunakan pada saat ini.

3. Pengkodean/ penulisan sinkode

program Masuk di tahap pengkodean dimana pada tahapan ini dilakukan penerjemahan design dalam bahasa yang bisa dikenali oleh komputer. Pada tahap inilah peneliti mulai melakukan penerapan program dan algoritma. Penulisan sin code program yang digunakan pada penelitian ini menggunakan bahasa program PHP.

4. Pengujian

Tahap keempat ini akan dilakukan penggabungan modul-modul yang sudah

dibuat sebelumnya. Setelah itu akan dilakukan pengujian yang bertujuan untuk mengetahui apakah software sudah sesuai desain yang diinginkan dan apakah masih ada kesalahan atau tidak, pada penelitian ini pengujian dilakukan dengan menggunakan pengujian Black Box.

5. Maintenance / Pemeliharaan sistem

Maintenance adalah tahapan terakhir dari metode pengembangan waterfall. Di sini software yang sudah jadi akan dijalankan atau dioperasikan oleh penggunanya, dan software juga membutuhkan pemeliharaan dan pengembangan untuk mengupdate perubahan dari eksternal perusahaan seperti ketika ada pergantian sistem operasi, atau perangkat lainnya

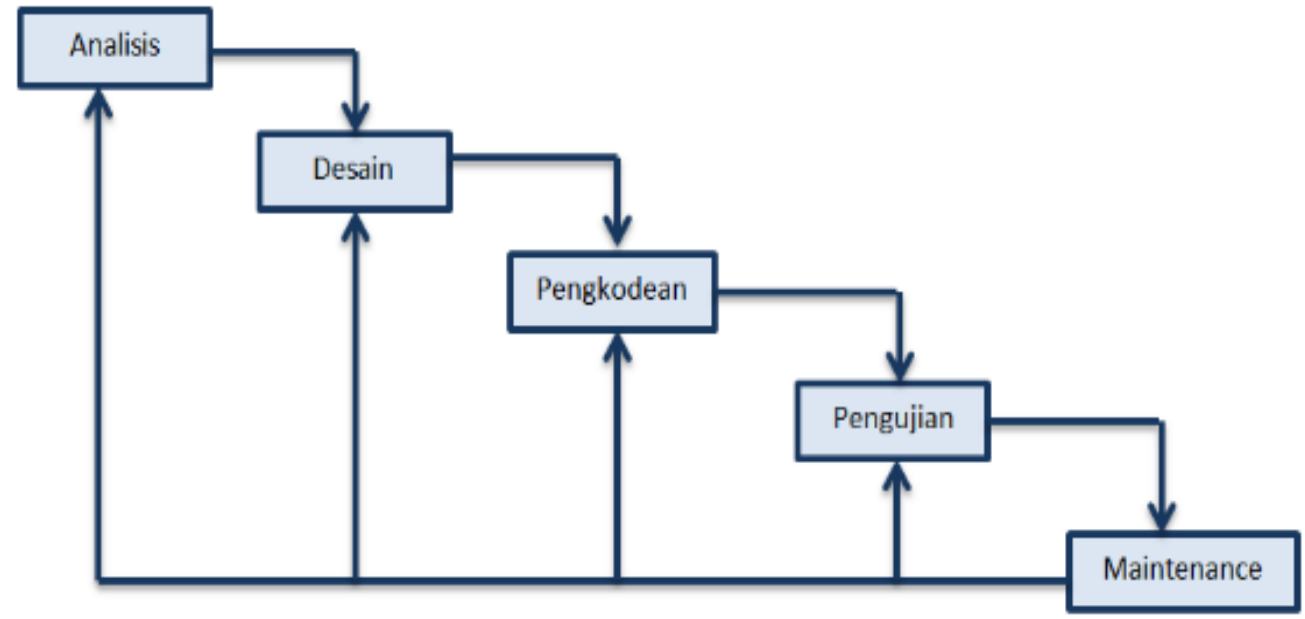

Gambar 1 Metode Waterfall

\section{HASIL DAN PEMBAHASAN}

Perancangan ini menggunakan Unified Modelling Language (UML) untuk menjelaskan prosedur, proses dan pemodelan untuk menjelaskan sistem yang dirancang. Adapun perancangan UML yang digunakan adalah merancang Flowchart, dan activity diagram. 


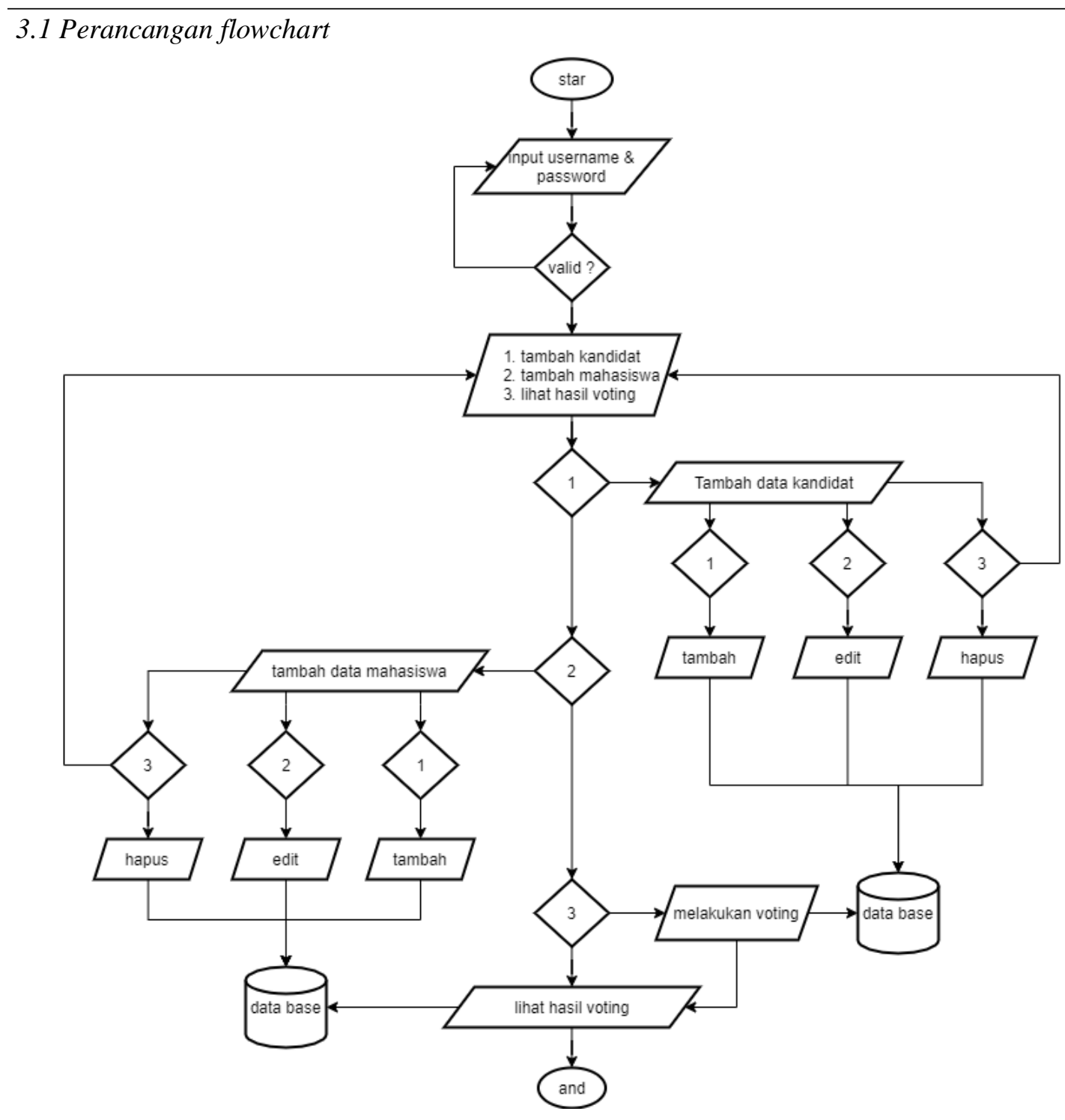

Gambar 2 perancangan Flowchart Sistem

3.2.1 Perancangan activity diagram login

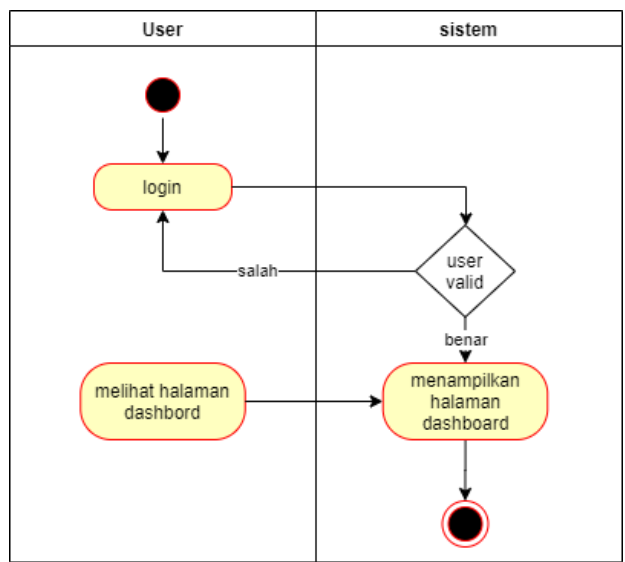

Gambar 3 perancangan activity diagram login 
3.2.2 Perancangan activity diagram tambah kandidat

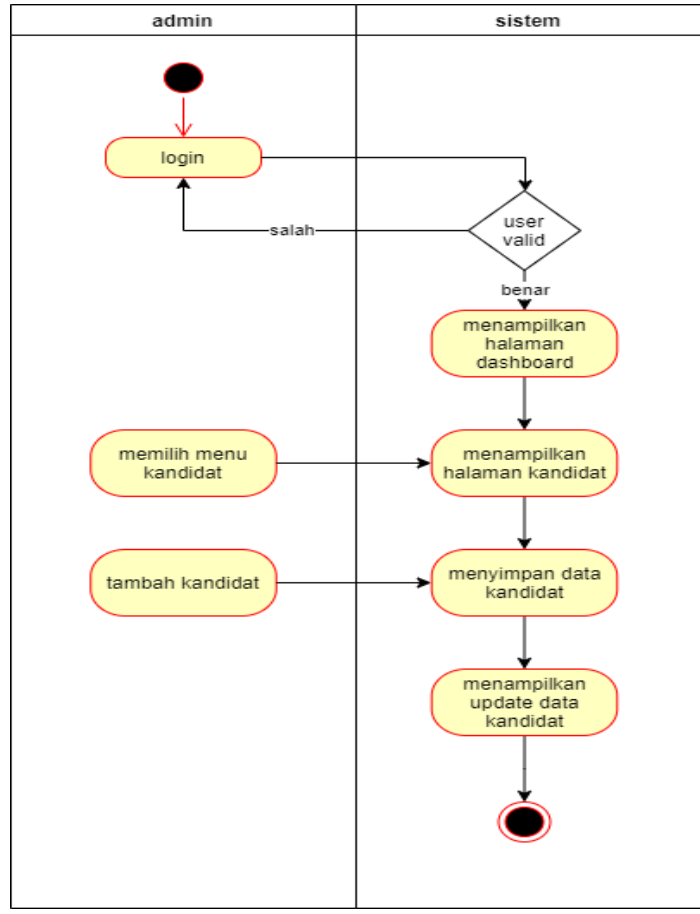

Gambar 4 activity diagram tambah kandidat

\subsubsection{Perancangan activity diagram tambah mahasiswa}

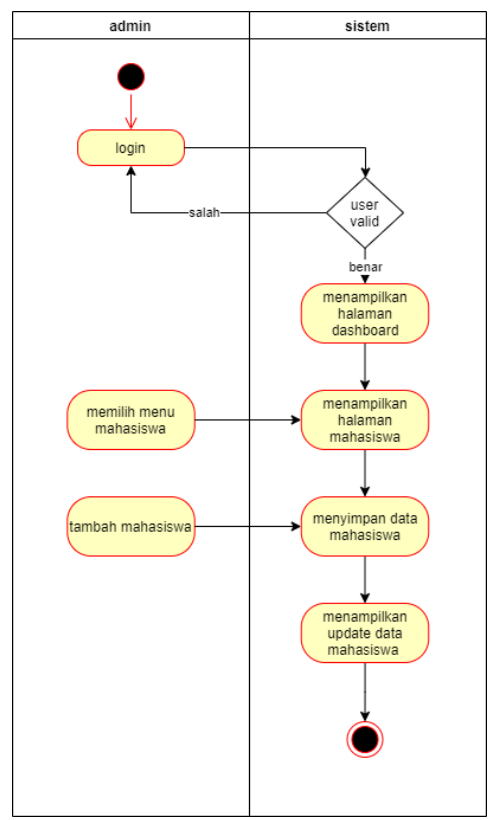

Gambar 5 activity diagram tambah mahasiswa 
3.2.4 Perancangan activity diagram voting mahasiswa

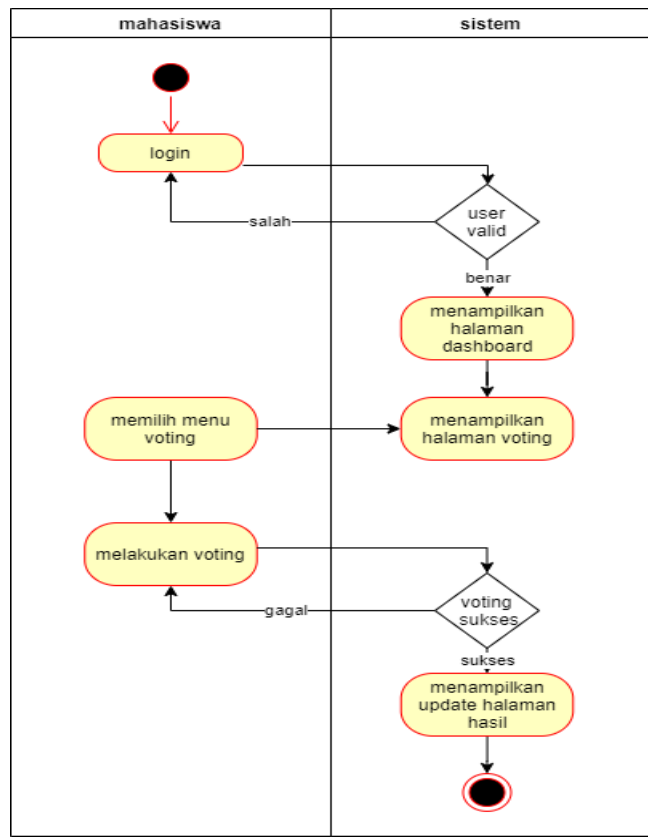

Gambar 6 activity diagram voting mahasiswa

\subsection{Implementasi Desain}

\subsubsection{Halaman login}

Tampilan login digunakan oleh user dan admin, didalam halaman ini user atau admin diminta memasukan username dan password, user name dan password ini didapatkan dari admin. Setelah username dan password telah diinput user dan admin dapat menekan button atau tombol login untuk mulai masuk ke tampilan halaman utama dari aplikasi voting. ketika username menekan tombol atau button login. jika salah dalam memasukan password atau username maka halaman akan tetap berada didalam login. sama halnya dengan admin bedanya hanya admin akan masuk ke tampilan admin yang sudah disediakan. Tampilan halaman login ada pada gambar 7 .

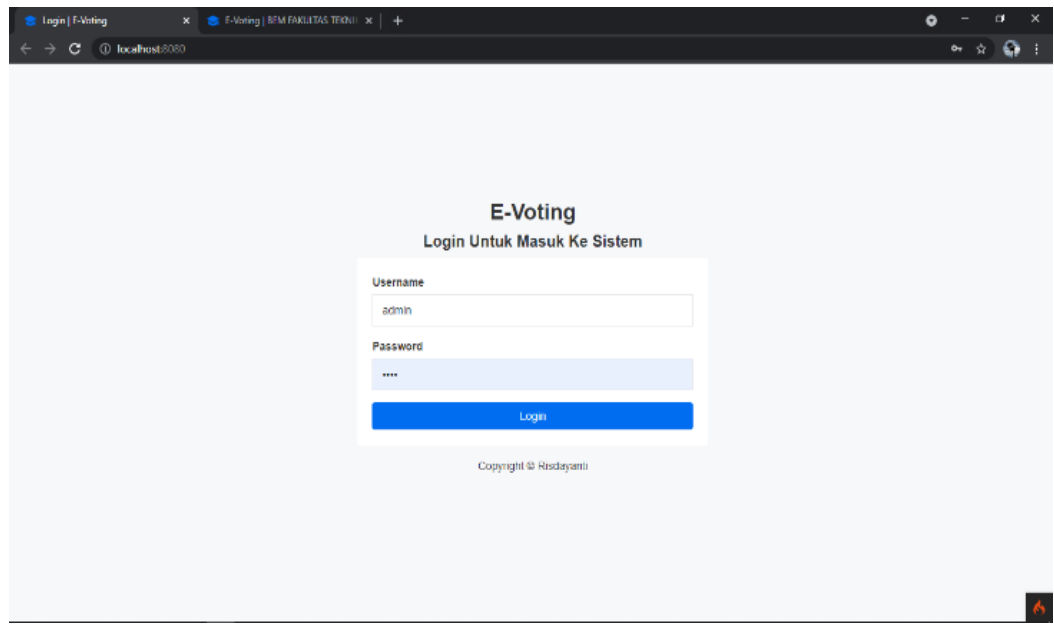

Gambar 7 Halaman login 


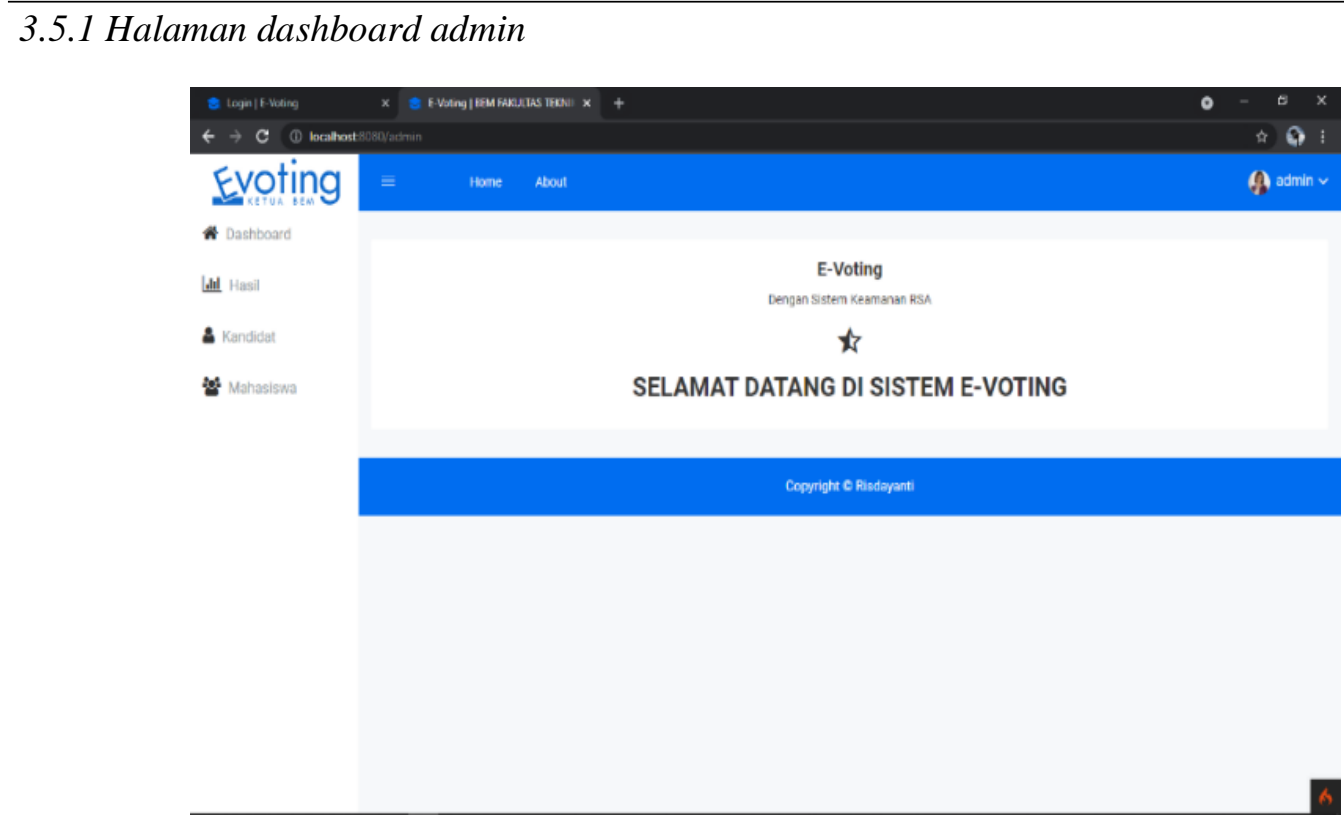

Gambar 8 Halaman dashboard admin

Tampilan halaman dashboard admin yang telah sukses melakukan login. dimana halaman ini menampilkan beberapa fitur diantaranya yaitu fitur hasil untuk melihat hasil voting, fitur kandita untuk menambahkan dan mengupdate data kandidat dan fitur mahasiswa untuk menambahkan peserta pemilih/mahasiswa.

\subsubsection{Halaman dashboard admin}

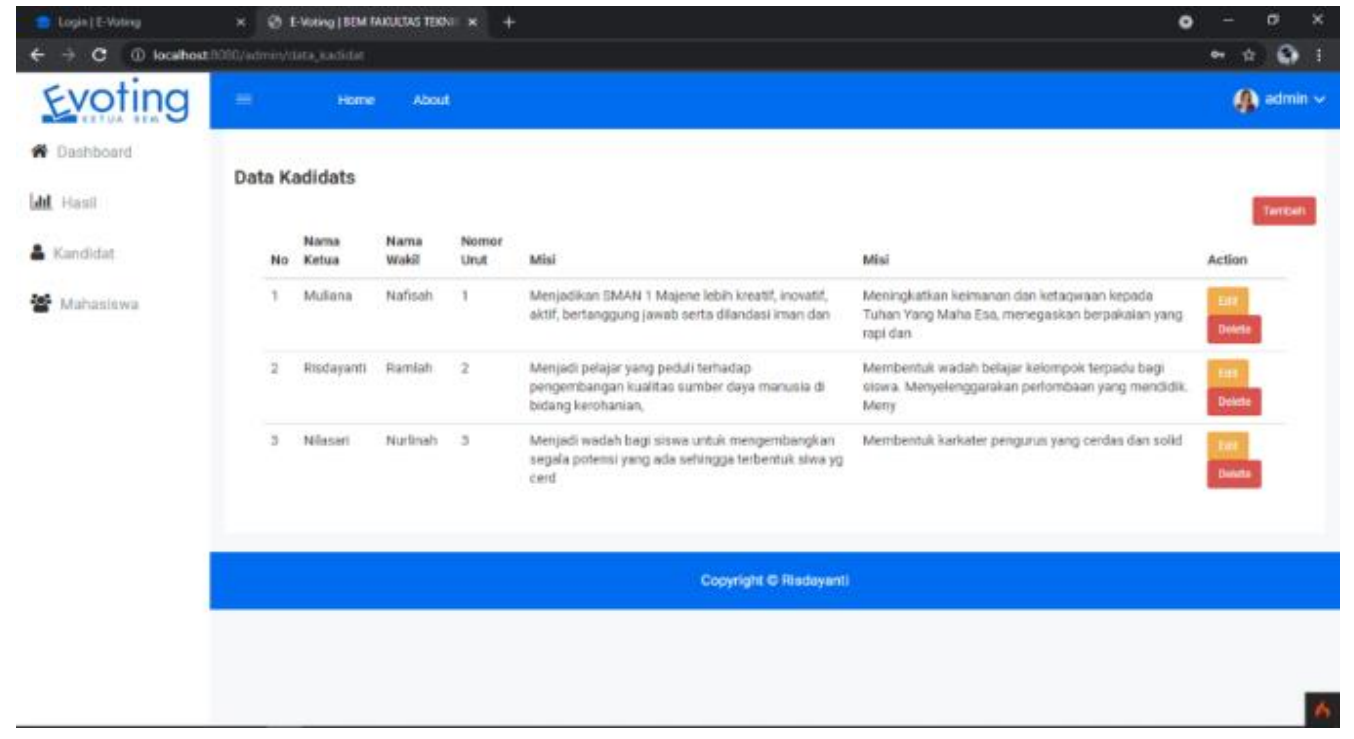

Gambar 9 Halaman dashboard admin 


\subsubsection{Halaman data mahasiswa}

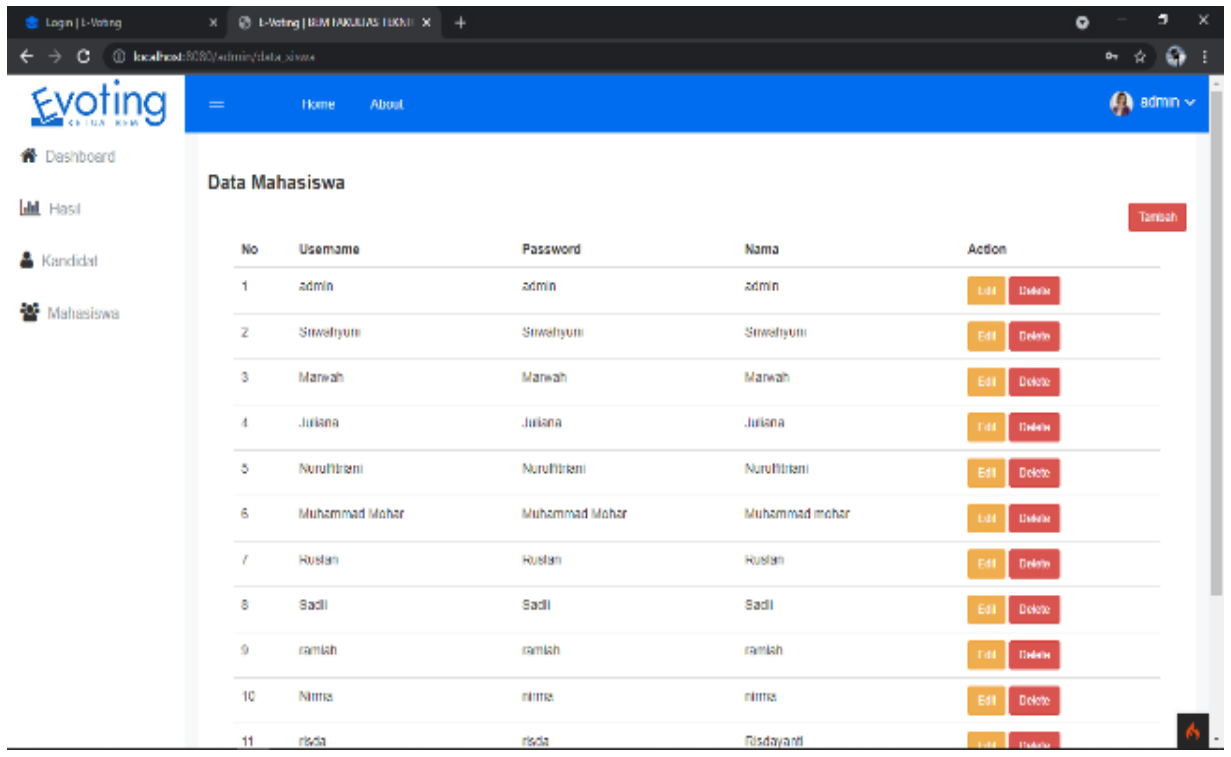

Gambar 10 Halaman data mahasiswa

Pada form mahasiswa, admin dapat mengelolah data mahasiswa/pemilih seperti menambahkan, mengedit dan menghapus.

\subsubsection{Halaman dashboard mahasiswa}

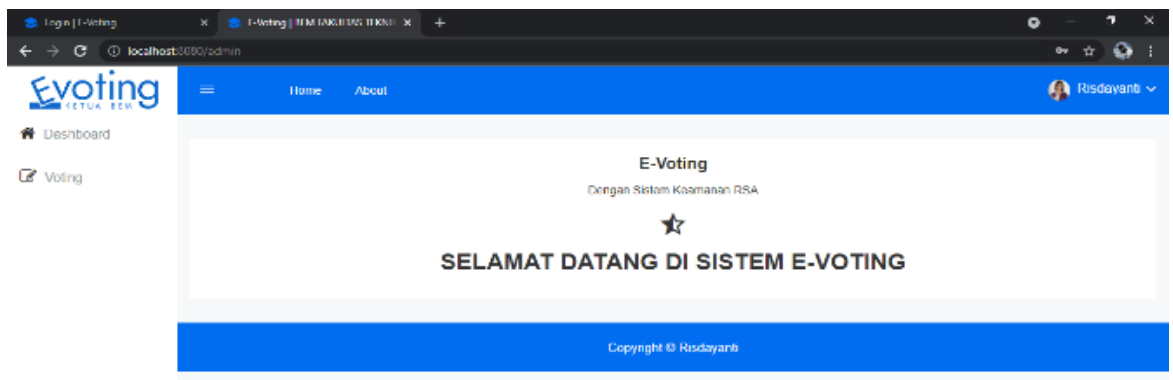

Gambar 11 Halaman dashboard mahasiswa merupakan halaman dashboard mahasiswa yang telah sukses melakukan login. 


\subsubsection{Halaman voting mahasiswa}

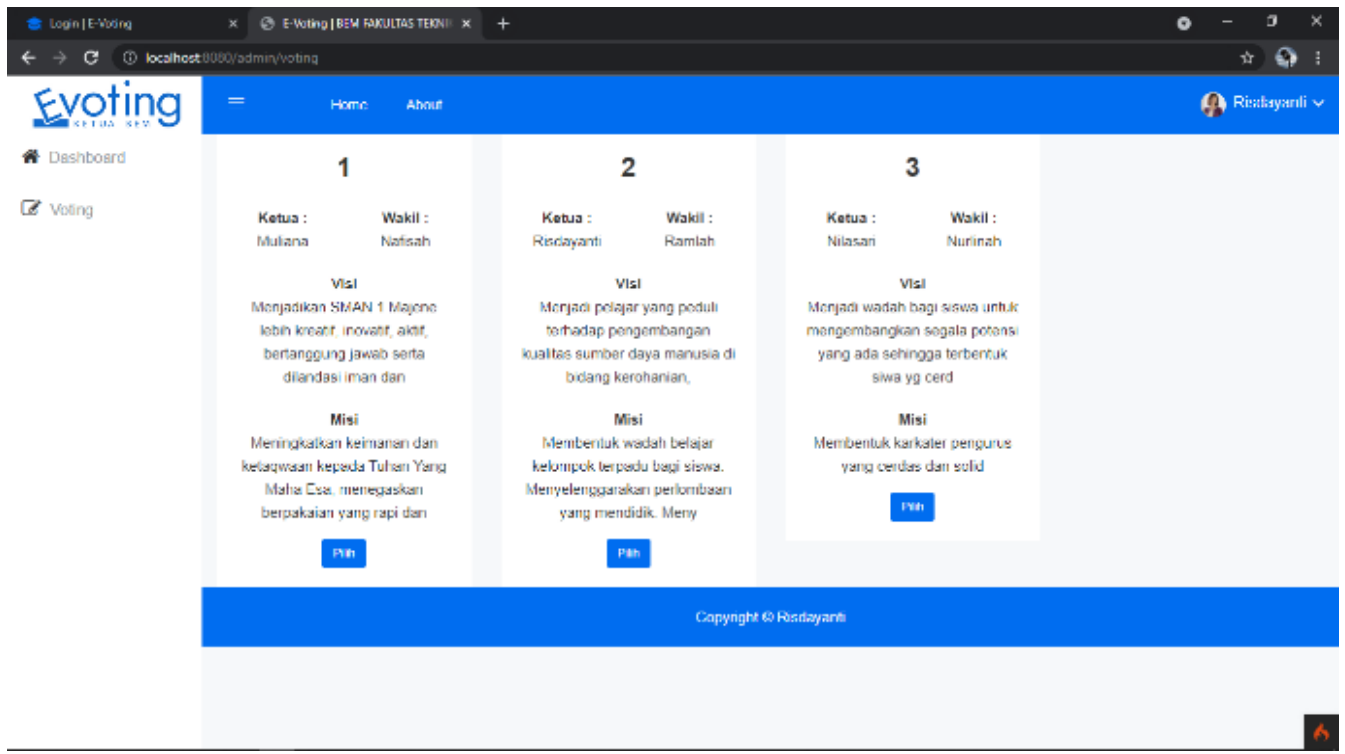

Gambar 12 Halaman voting mahasiswa

Pada gambar 12 merupakan gambar halaman voting menu ini dirancang agar pemilih dapat menggunakan hak pilih untuk memilih pasangan calon yang ingin dipilih, ketika pemilih telah menentukan pilihan pasangan calon ketua BEM maka klik tombol pilih maka akan menyimpan dan tak bisa digagalkan. Setelah pemilih menekan tombol pilih maka otomatis halaman voting akan berubah menjadi halaman hasil, jadi kesempatan user memilih hanya 1 suara setiap memilih, fungsi dari ini adalah agar pemilih tidak bisa memilih dua kali dan di halaman ini pemilih dapat melihat visi dan misi dari pasangan calon yang mendaftarkan untuk menjadi ketua BEM Fakultas Teknik.

\subsubsection{Halaman tampilan hasil voting}

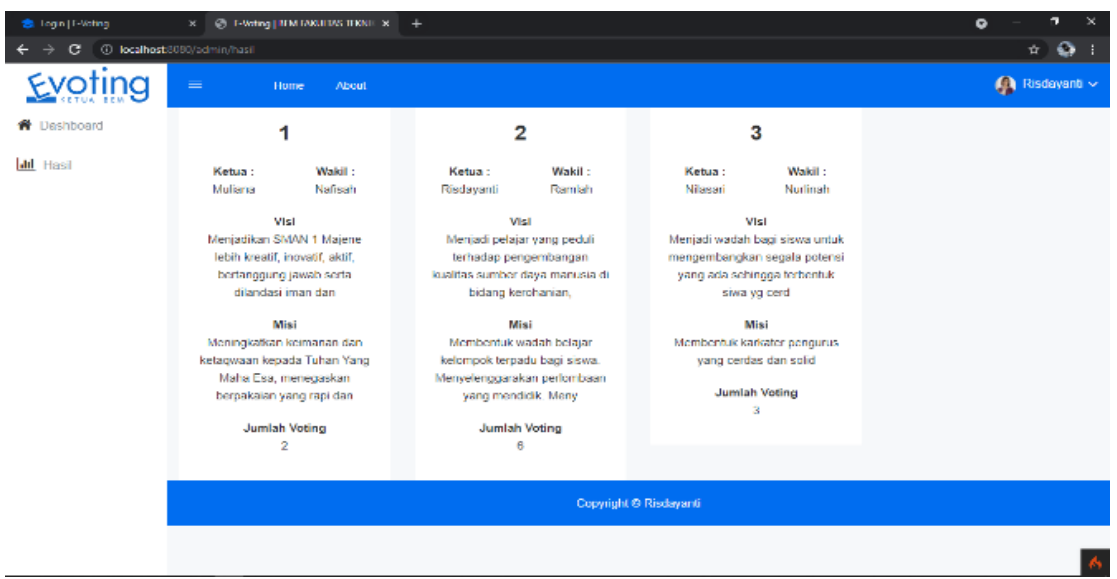

Gambar 13 Halaman tampilan hasil voting 
Pada gambar 13 merupakan gambar halaman hasil voting ini adalah halaman untuk melihat perolehan suara yang masuk.

\subsection{Pengujian}

Langkah selanjutnya adalah melakukan tahap pengujian sistem. Pada tahap pengujian sistem ini penulis melakukan pengujian terhadap setiap fungsi-fungsi yang ada. Metode pengujian yang digunakan yaitu metode black box testing. Pengujian black box menguji keseluruhan menumenu dan yang ada sistem. Berdasarkan uji blackbox yang dilakukan, sistem dapat berjalan sesuai dengan yang diharapkan tanpa ada malfunction dari semua menu yang ada pada sistem.

\section{KESIMPULAN}

Berdasarkan penelitian yang telah dilakukan, peneliti menarik beberapa kesimpulan diantaranya adalah sistem e-voting yang dibangun mengurangi permasalahan proses pemungutan suara yang sebelumnya didapat dalam bentuk kertas. Penggunaan database pada sistem e-voting sebagai penyimpanan data, mempermudah pengolahan data warga, pemilihan hingga perhitungan suara. Sistem e-voting dapat menghasilkan pemungutan suara yang tepat dan cepat sehingga dapat meminimalkan kecurangan.

\section{REFERENSI}

[1] D Lavarino. 2016. Rancang Bangun E-Voting Berbasis Website di Universitas Negeri Surabaya. Jurnal Manajemen Informasi. Vol.6, No.1, hal. 72-81

[2] FA Syam, Y Darmayunata. 2019. Perancangan Sistem E-Voting Untuk Pemilihan Ketua OSIS SMP Negeri 10 Pekanbaru. Jurnal Sistem Informasi. Vol. 1, No. 2, hal. 75-85

[3] Hidayat, D., dan Prabowo, D. W. 2017. Sistem Informasi E-Commerce Di Cv. Galaxy Computer Bebrasis Php \& Mysql.Vol. 7, N0. 2. (jurnal.unda.ac.id, di akses 15 Juli 2020)

[4] Jaya, F., Yuliana, D., \& Kholidy, K. (2020). Rancang Bangun Aplikasi E-Voting Berbasis Web Pada Pemilihan Ketua Dan Wakil Ketua Osis Di Smk Ibnu Kholdun Al Hasyimi. Edusaintek: Jurnal Pendidikan, Sains Dan Teknologi, 7(1), 54-67. https://doi.org/10.47668/edusaintek.v7i1.60

[5] Kasemin kasiyanto. 2015. Agresi Perkembangan Teknologi Informasi. Prenada Media Group: Jakarta

[6] Kirana Chandra, Suci Amalia. 2018. Rancang Bangun Aplikasi MVoting Untuk Pemilihan Ketua OSIS Di Ma Darussalam Pangkalpinang Berbasis Smartphone Android. Jurnal Informatika Vol. 1, oktober 2018.

[7] R Prananda, H Anra, HS Pratiwi. 2017. Rancang Bangun Aplikasi EVoting Berbasis Android (Studi Kasus: Pemilihan Ketua Organiasi di Lingkungan Fakultas Teknik Universitas Tanjungpura). Jurnal Sistem dan Teknologi Informasi, vol. 5, No. 1, hal. 17 - 21.

[8] Rokhman, A. (2011). Prospek dan tantangan penerapan e-voting di indonesia. In Seminar Nasional Peran Negara dan masyarakat dalam Pembangunan Demokrasi dan Masyarakat madani di indonesia (Vol. 7, pp. 1-11)..

[9] Saputro,H W. 2007. Definisi dan Pengertian Web Menurut Para Ahli. http://www.sambureki.com/definisi/definisi-dan-pengertian-web-menurut- para-ahli.html. Diakses pada tanggal 2 April 2015 13.30 Wita.

[10] SY Hasyrif, Rismayani. 2018. "Penerapan Konsep MVC Pada Aplikasi Web Menggunakan Framework Laravel." Prosiding Seminar Ilmiah Sistem Informasi Dan Teknologi Informasi 5(2): 174-83 